\title{
Festival com vista para as fronteiras
}

\section{Jorge Louraço Figueira}

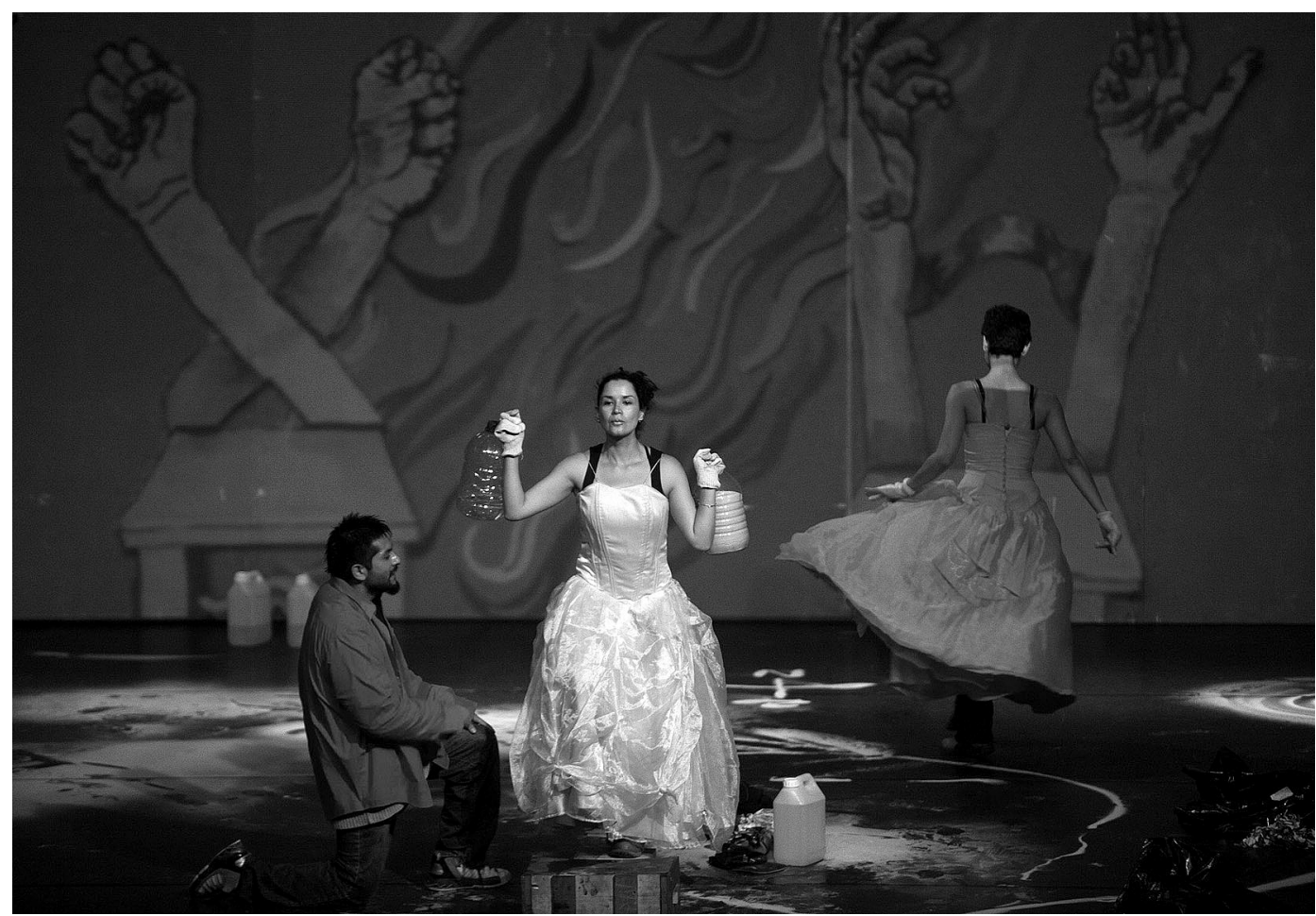

0 Mirada 2012, festival de teatro ibero-americano de Santos, entre 5 e 15 de Setembro, foi uma oportunidade única para ver o melhor do teatro mexicano e ainda ter uma amostra representativa da produção teatral da América Latina.

1. Festival com vista para as fronteiras 0 festival Mirada trouxe à cidade de Santos uma visão panorâmica sobre o teatro mexicano, e, indirectamente, o México, essa paisagem interrompida por fronteiras artificiais e cruzada pelo tráfico de pessoas e drogas. Amarillo, do Teatro Línea de Sombra, e Incendios, de Wajdi Mouawad, pela Compañia Tapioca Inn, causaram furor. Além dos espectáculos e painéis de debate sobre o pais homenageado, no Mirada viram-se ainda obras emblemáticas de alguns dos mais antigos e importantes grupos da América Latina, desde Sín título, técnica mixta, dos peruanos Yuyachkani, a Acto cultural, dos venezuelanos Actoral 80, passando por Gemelos, dos chilenos Teatro Cinema, sucessores de La Troppa, ou por Hamlet, de Los
Andes, o último trabalho do renovado Teatro de los Andes, da Bolívia.

Houve também lugar para estrelas em ascensão, como o colectivo La Maldita Vanidad, da Colômbia, que tem corrido mundo com a sua trilogia naturalista Sobre algunos asuntos de familia, composta pelas peças El autor intelectual, Los autores materiales e Como quieres que te quiera. De Portugal, apresentaram-se os Artistas Unidos, com Herodíades, produção deste ano, e de Espanha, os catalães Els Joglars, com a remontagem de El nacional, estreada no início dos anos noventa.

Promovido bienalmente pelo SESC (Serviço Social do Comércio) de São Paulo, o festival duplicou de tamanho nesta segunda edição, com 14 paises representados, 38 espectáculos (15 do Brasil) e 100 mil espectadores (numa cidade de meio milhão de pessoas, mas que é destino turístico dos paulistanos). 0 Mirada fez jus ao nome, apresentando uma vista sobre as diferenças e as semelhanças culturais no universo teatral ibero-americano, e devolvendo, tanto ao público como aos artistas, críticos
Jorge Louraço Figueira escreveu Cassandra de Balaclava (2013), Xmas qd Kiseres* (2002) e $O$ espantalho teso (2000) entre outras peças; é doutorando em Estudos Artisticos na Universidade de Coimbra (com bolsa da FCT), dramaturgo residente d'0 Teatrão - Oficina Municipal de Teatro, docente da ESMAE [Escola Superior de Música e das Artes do Espectáculo, do Porto] e crítico de teatro do jornal Público. 


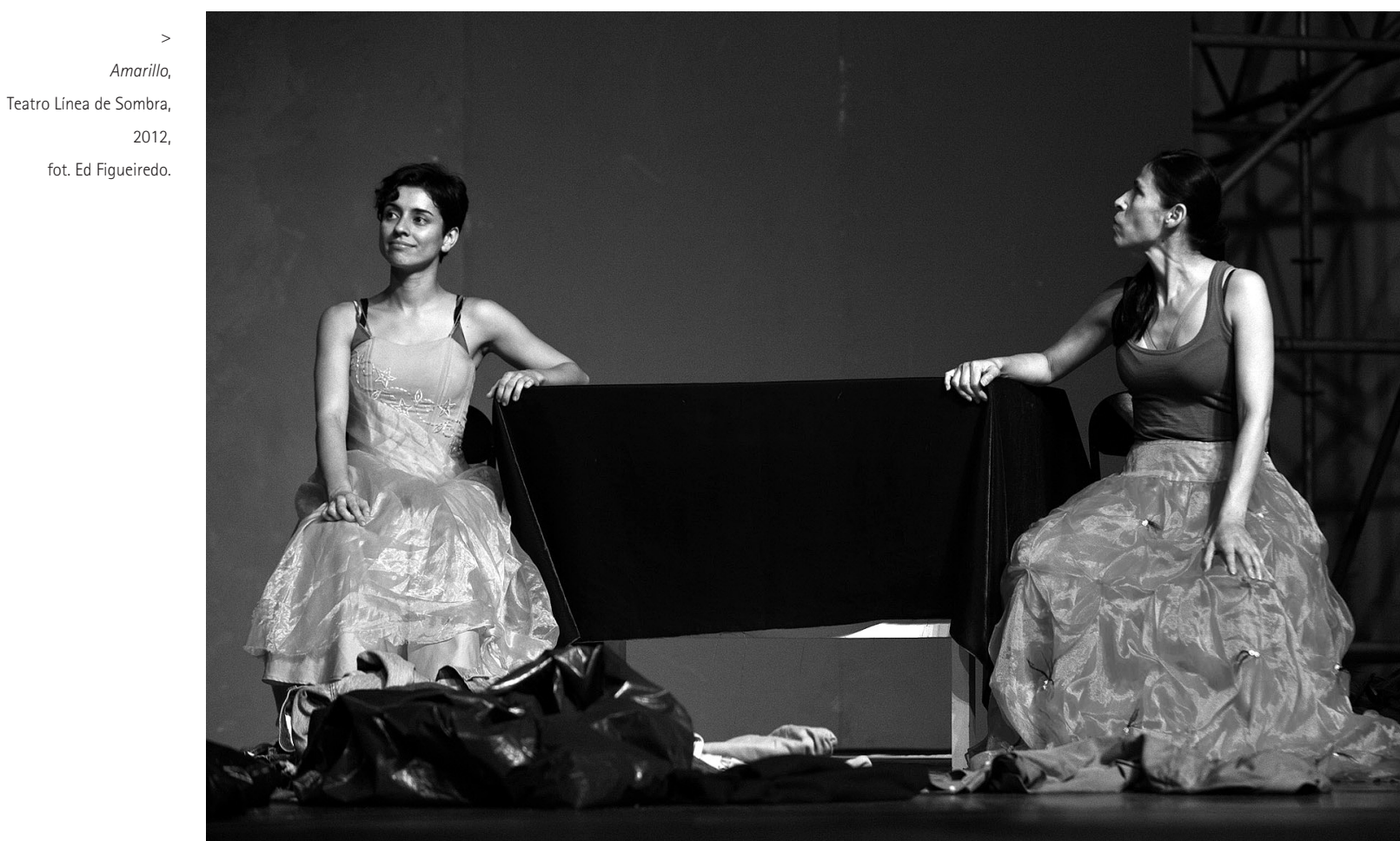

e programadores, imagens dos vários países da América Latina que puderam estar presentes.

A cidade de Santos é, hoje em dia, o maior porto marítimo da América Latina e, segundo a organização do festival, capital simbólica do encontro de culturas no continente, razão pela qual foi escolhida para sediar este evento (criado à imagem e semelhança do Festival Iberoamericano de Cádis, este ano na $27^{2}$ edição).

A cidade é conhecida por ter destronado o Rio de Janeiro como principal porto de exportação de café na segunda metade do séc. XIX, o que pode ser comprovado numa visita ao Museu do Café, instalado na antiga bolsa cafezeira, dos anos vinte, onde eram arrematados os lotes e definidos os preços do grão. No início do séc. XX, Santos foi alvo de renovação urbana, com a construção de uma série de canais e vilas, e a destruição dos cortiços onde se albergavam os imigrantes europeus e os ex-escravos. É também famosa pela orla marítima pontuada por cerca de cem prédios tortos, cuja inclinação chega a dois graus (metade da inclinação da Torre de Pisa). E claro, pelo clube de futebol de Pelé.

A viagem de São Paulo para a baixada santista demora de uma a quatro horas, conforme o trânsito de camiões de mercadorias e de turistas destinados à estância balnear do Guarujá. Os dias, porém, não estavam para banhos de mar, e os passeios foram mais entre o SESC (Serviço Socia do Comércio) Santos, perto da barra, com dois auditórios, e os teatros Brás Cubas, Guarany e Coliseu, no centro histórico, para poder ver todos os espectáculos. Um galpão anexo ao Coliseu e a Casa da Frontaria Azulejada foram também ocupados pelo festival.

"Eu olho para o Norte. Mas o Norte não olha para mim."

Tijuana, Ciudad Juarez, Chihuahua, Amarillo - os nomes do território fronteiriço do México ecoam muito depois de terem parado os gritos das vítimas da migração clandestina, do narcotráfico e da corrupção. Amarillo é uma cidade do Texas, para onde se dirigem muitos dos emigrantes clandestinos que atravessam o deserto - e também o nome de um dos espectáculos mais aclamados da selecção mexicana. A peça do Teatro Línea de Sombra conta a história de um homem que partiu e de uma mulher que reconstrói a sua presença à distância, imaginando o itinerário, o corpo e as falas do ausente. Um jovem actor representa este Ulisses moderno, com todos os nomes e todos os caminhos, uma espécie de Zé-ninguém que vale pelos demais. Três actrizes dançam as Penélopes de hoje, recordando o tempo antes da partida e imaginando os regressos. Um homem mais velho, com a figura do típico camponês mexicano, entoa cânticos guturais como se fosse um coro grego. É uma obra maravilhosa, de teatrodança, se a quisermos classificar, mas na verdade sem fronteiras fisicas nem artísticas, que expande a ideia de teatro para lá do imaginável, como se a tragédia grega tivesse voltado do futuro.

0 trabalho foi feito a partir daquilo a que chamaram o kit do emigrante: um par de ténis, um cantil de água, um chapéu. Essa "objectualidade própria gerou micronarrativas que conduziram depois a uma estrutura", revelou o encenador, Jorge A. Vargas. Amarillo começou a ser criado a partir de uma experiência familiar, mas o resultado levou a que o grupo de teatro tenha passado a fazer, nos projectos seguintes, um "trabalho de contexto, sem mediação de um texto ou de um edifício teatral, onde primeiro vem a relação, depois o resultado. Um teatro expandido, criado in situ". Na época ainda não se conheciam tão bem o negócio de extorsão dos familiares dos emigrantes, os campos de concentração onde ficam retidos, as valas comuns. "Amarillo é, num certo sentido, anacrónico, porque foi criado quando ainda não se sabia tudo, e corre o risco de ser apenas porno-miséria, exibindo a realidade e pronto. Mas esse é o dilema ético do artista: se fala demais, esvazia o tema". 


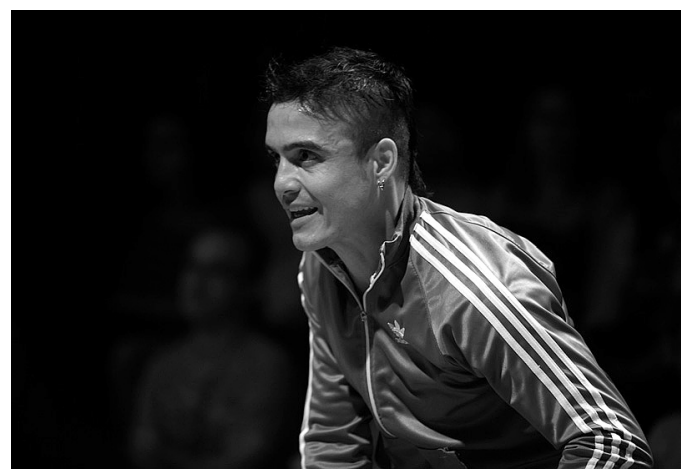

"Lutar contra a miséria do mundo, talvez, ou então cair dentro dela."

Nas filas para entrar, para levantar os bilhetes ou para ficar em lista de espera (aqui chamada fila da esperança), escutavam-se os mais elogiosos comentários precisamente para Amarillo, bem como para Incendios, da Compañia Tapioca Inn. 0 reconhecimento foi tal que ambos serão apresentados em São Paulo no próximo ano. Mário Moutinho, director do FITEl, que esteve presente em todo o festival, gostaria de levá-las ao Porto.

Incendios, da companhia mexicana Tapioca Inn, apresentado no galpão do Teatro Coliseu, deixou os espectadores de olhos marejados. A peça original, de Wajdi Mouawad, franco-libanês radicado no Quebeque, conta a história de um irmão e uma irmã, gémeos falsos, que buscam o pai e um meio-irmão, perdidos durante a guerra do Libano (o filme feito a partir da peça ganhou o Óscar de melhor filme estrangeiro em 2011). No coração da peça, em parte baseada em factos reais, está uma tragédia de contornos edipianos que surpreende o espectador mais avisado. 0 pai e o irmão são uma e a mesma pessoa, e os gémeos fruto da violação da mãe num centro de tortura onde o próprio filho era o torturador. A versão mexicana desta história de refugiados, paramilitares e exércitos de ocupação reverbera na história de mais do que um pais, e certamente na do México. Com encenação de Hugo Arrevillaga Serrano, a actuação é feita com tal rigor que o público não pôde deixar de se comover com o mundo emocional das personagens.

Uma vez mais, por favor, de Michel Tremblay, talvez o mais importante dramaturgo do Canadá, é um diálogo biográfico entre o autor, tímido, e a sua mãe, espaventosa, escrita em jeito de despedida. As várias vinhetas, que vão da infância do narrador à morte da matriarca, apresentam os exageros melodramáticos e a imaginação delirante da mãe como sendo a origem da inventividade do autor. 0 espectáculo é jogado com um ritmo preciso pelos premiados

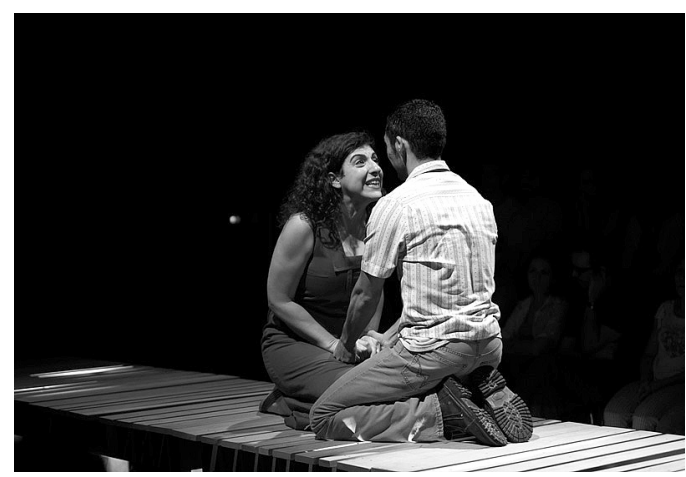

$<>$

Incendios,

de Wajdi Mouawad,

Compañia Tapioca Inn, 2012,

fot. Fernanda Procopio.
Angelina Peláez e Arturo Beristain, sob a direcção de Mario Espinosa, para a Compañia Nacional de Teatro. 0 pequeno quarto ao final da escada, do Teatro El Farfullero, com a mesma actriz principal de Incendios, foi a terceira produção mexicana a partir de uma peça canadiana apresentada no festival. (A presença da dramaturgia canadiana, em especial do Quebeque, no México, é grande, segundo disseram membros da comitiva oficial mexicana). Inspirada na fábula do Barba Azul, o espectáculo abre espaço para a imaginação ao deixar no ar a questão da origem da maldade do lendário assassino. Mais uma vez, a imaginação e o exagero das personagens femininas parece ser a condição sine qua non para viver o real. Ambas são dramas familiares.

\section{"Chihuahua é uma ilha."}

Los Asesinos, de David Olguin, co-produção do teatro El Milagro, uma das salas independentes da Cidade do México, e do Carretera 45, um grupo de Ciudad Juarez que mudou para a capital, retomou o tema da violência relacionada com o tráfico e a emigração. A narrativa salta no tempo para mostrar os sucessivos assassinatos e o modo como a sede de matar domina os 'sicarios: matadores profissionais. As personagens precipitam-se na euforia do assassinato, disparando sobre o outro a qualquer momento, e depois expondo os mortos com gosto. 0 autor e encenador apropriou-se da pronúncia e gíria do norte do México, de onde veio a maior parte do elenco, para criar um lirismo próprio, capaz de expressar essa cegueira assassina. A peça é uma alegoria da situação actual, com a história de uma quadrilha de traficantes, liderada por uma viúva, em primeiro plano, e a relação enredada do México com os EUA por trás. As personagens encontramse num território isolado, cenário da guerra contra o tráfico, onde o perigo de morte torna as acções ridículas e as falas absurdas. 0 resultado é um poço da morte num mundo à parte, que nos ajuda a penetrar no mistério da mortandade diária que assola o México. 
Los asesinos,

de David Olguin,

Teatro El Milagro

Carretera 45

2012

fot. Ed Figueiredo.

El dragón dorado, de Roland Schimmelpfennig, dirigido por Daniel Giménez Cacho (também do teatro El Milagro), para as Por Piedad Producciones; e Ensayo sobre débiles, de (e dirigido por) Alberto Villarreal, peça escrita durante uma residência internacional no Royal Court Theatre, encerraram a programação mexicana. Ambas estão sob o signo de Pirandello, explorando o que o espectador conhece das convenções teatrais para surpreender com uma fiç̧ão renovada. 0 primeiro texto, sobre a difícil convivência de um emigrante num restaurante oriental, tem as indicações de cena nas falas das personagens, o que permite que, por exemplo, uma personagem masculina, mais velha, seja feita por uma actriz muito nova. A estranheza da cena sai reforçada. 0 segundo espectáculo discorre sobre a natureza do trabalho do actor, passando por cenas de expulsão como as vistas nos reality shows, e culminando num pedido aos espectadores para fazerem confissões pessoais, o que aconteceu com relativa naturalidade.

\section{0 mistério do México visto do teatro}

0 México é o pais onde as os cartéis da droga patrocinam os narcocorridos, canções sobre a vida dos traficantes, e o videohome, ou Narco Cinema, a produção de filmes de muito baixo orçamento que vão directo para os leitores de vídeo, revelou Antonio Veja Barragan no debate sobre "A violência urbana e a migração como objectos de interesse para a criação teatral mexicana". 0 mesmo México onde há voluntárias, as patronas, que ajudam os desconhecidos ao longo da trilha da emigração a caminho dos EUA, e os passadores, chamados coyotes, que capturam esses mesmos emigrantes para extorquir dinheiro às familias, acrescentou o dramaturgo David Olguín. A morte é olhada de frente pelos mexicanos, a julgar pelas peças do Mirada. A tragédia dos rituais précolombianos e o melodrama da paixão cristã parecem ter-se fundido numa teatralidade muito própria, capaz
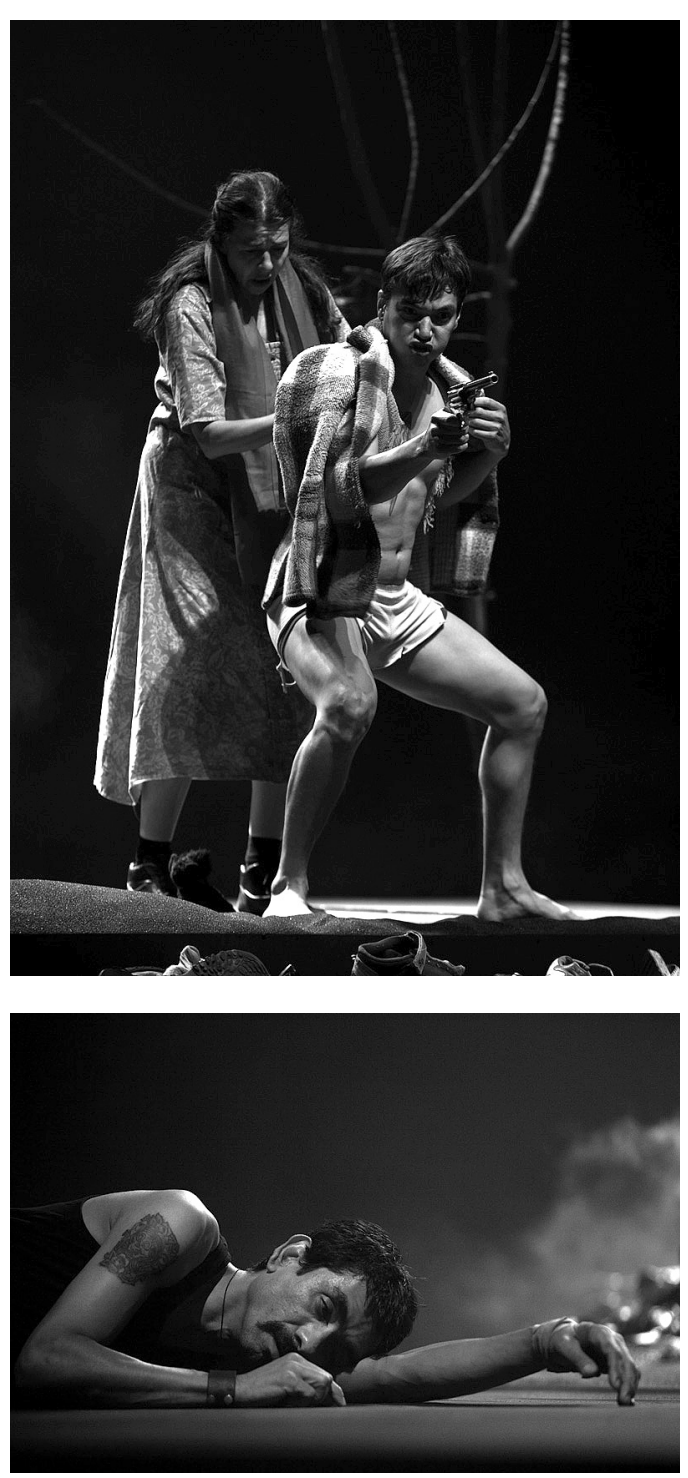

de assustar, comover e fazer rir ao mesmo tempo. Haverá alguma relação entre a celebração festiva da morte, no Dia de los muertos, a 2 de Novembro, e a aparente banalização do homicídio (entre 100 a 150 mil mortes de causa violenta desde 2006)?

Ileana Diéguez Caballero, radicada no México, autora de Cenários liminares: Teatralidades, performances e politica (2007), um dos estudos mais importantes sobre o teatro ibero-americano, quando questionada sobre como tratava o teatro mexicano o tema da morte, afirmou que "o teatro que se faz não se articula com o cultural, em especial com as representações da morte. 0 teatro mexicano tem vivido de costas para a cultura popular. 0 México é um pais de muita teatralidade, mas não de muito teatro". A questão é controversa. Para Vivian Tabares, directora de revista Conjunto, ex-adida cultural da embaixada de Cuba no México, o teatro mexicano, pelo contrário, tem "uma relação com a realidade. Há pesquisa de identidade porque há uma comunhão com os espectadores".

0 teatro mexicano produz tanto a partir de temas locais como de textos dramáticos nacionais e estrangeiros, seja com estratégias de criação próprias seja com técnicas mais ou menos convencionais. 0 sistema teatral assenta numa rede de teatros públicos, nacionais ou regionais, e 

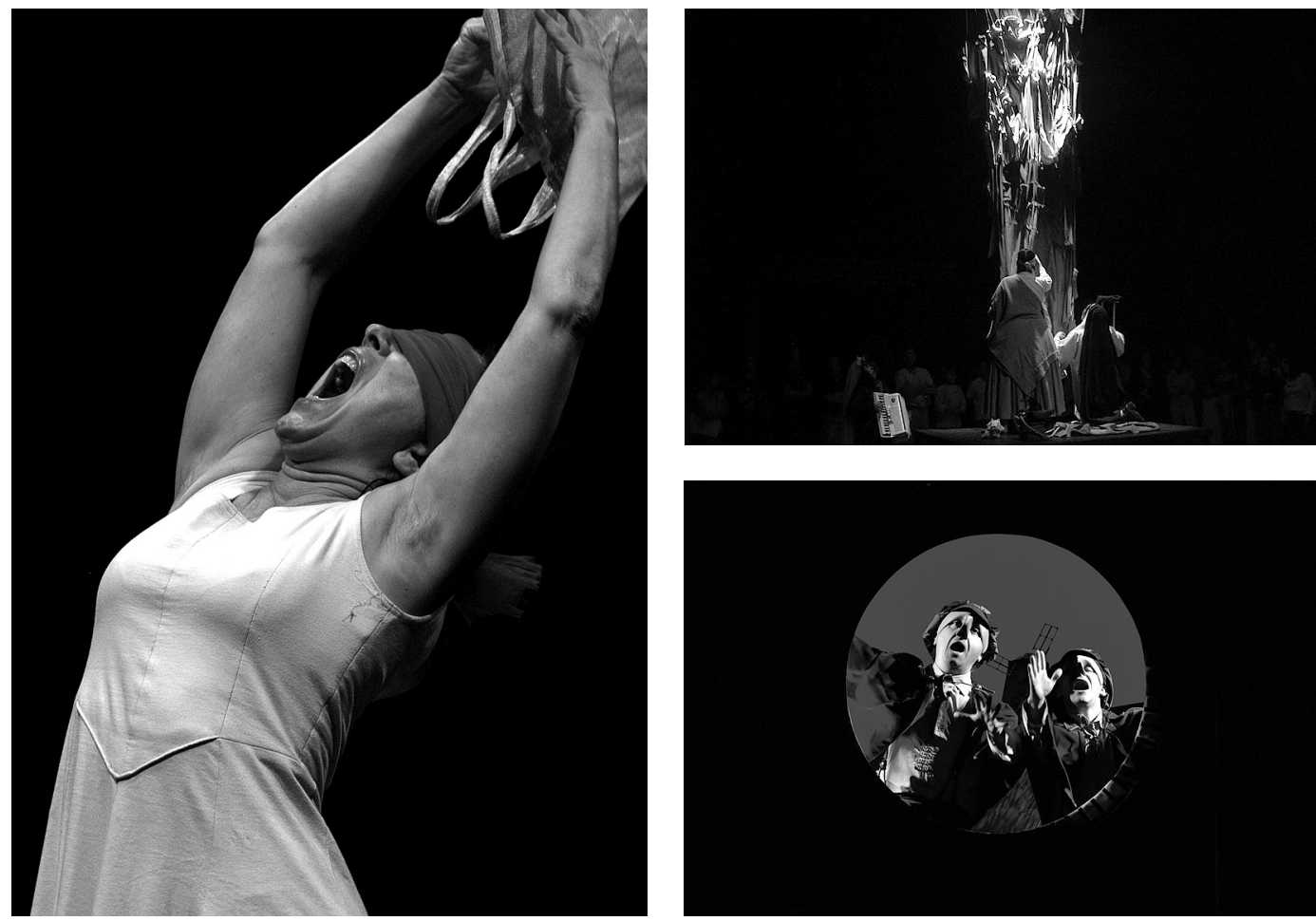

$<>$

Sin titulo, técnica mixto

Yuyachkani, 2012

fot. Elsa Estremadoyro.

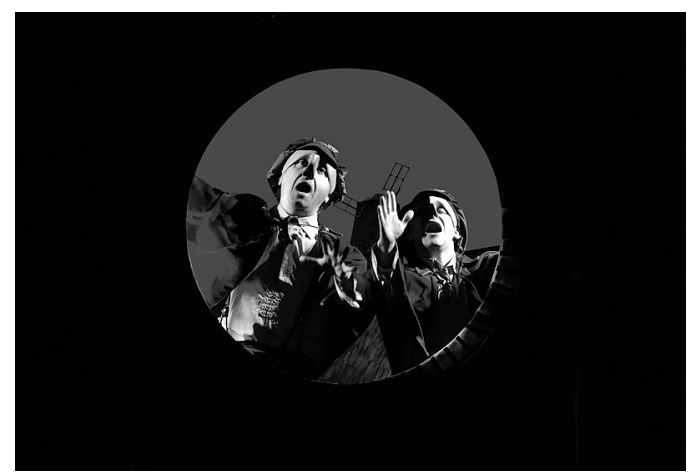

Gemelos,

Teatro Cinema, 2012 fot. Monserrat Quezada.
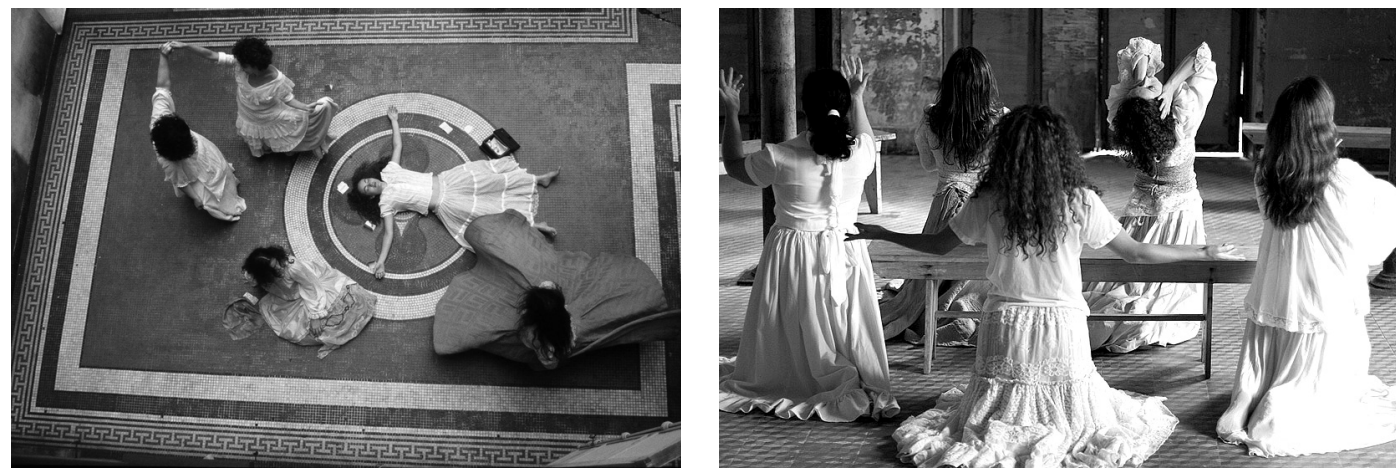

$>$

só mais recentemente no apoio directo a grupos e companhias. Um dos eixos desse sistema é a Mostra Nacional de Teatro, um grande festival que junta obras de todo o pais, e onde também se realizam oficinas e conferências. Este ano, na sua 33a edição, a Mostra apresentará 35 espectáculos escolhidos a partir de um lote de 300 candidatos (de que são parte estes seis espectáculos). Por ver ficaram, entre outros, textos de dramaturgos como Sabina Bergman, Jaime Chabaud ou Alejandro Ricaño; espectáculos de Las Lagartijas Tiradas al Sol, do Grupo Ojo ou de La Rendija; os números de cabareteras como Astrid Hadad, Jesusa Rodriguez e Regina Orozco e ainda Conchi Léon, de Mestiza Power, ou Guillermo Gomez-Peña, o mais célebre cultor do spanglish.

Inaugurado em 2010 com a Argentina com pais-tema, o Mirada prossegue na senda de desvendar os teatros que se fazem em cada cultura nacional para dar conta das contradições políticas e culturais de cada país. Em 2014 será a vez do Chile, de onde tem saído muito do melhor teatro da actualidade.

\section{Recomendações desejáveis}

Dos espectáculos apresentados no Mirada há dois que já foram vistos em Portugal: A primeira vista, de Daniel

Maclvor, com encenação de Enrique Diaz, dias 1 e 2 de Dezembro de 2012 no TNDM II; e Hysteria, do grupo XIX, em 2004, no FITEl, no Porto, e, este ano, na Mostra São Palco, dias 8 e 9 de Junho, em Coimbra, na Oficina Municipal de Teatro, e dia 10 em Torres Novas, no Cine-Teatro Virginia.

Esta última obra é um clássico do chamado "Teatro de Grupo" de São Paulo, a não perder sob circunstância alguma. Passada num sanatório feminino, no final do séc. XIX, a acção da peça permite aos espectadores assistir a um pedaço da vida de cinco mulheres diagnosticadas com histeria. Assistir, no caso dos homens, e participar também, no caso das mulheres: os dois públicos são separados no início do espectáculo, e enquanto as mulheres se sentam com as actrizes, os homens ficam a ver de longe. Estreada há doze anos, Hysteria funciona como uma máquina de precisão. Desde a relação das actrizes com os espectadores, ao entrelaçar os testemunhos e documentos reais com o texto, passando pelo ritmo emocional da encenação, sem som nem luz artificiais, tudo é exemplar neste espectáculo.

Do México, Amarillo e Incendios estavam previstos para o FITEI, no Porto, mas foram cancelados quando o festival perdeu o apoio da DGArtes.

Os três, de três países diferentes, que a seguir se destacam, valeria a pena serem vistos por cá..
Hysteria,

grupo XIX, 2012 fot. Adalberto Lima 
Hamlet, de los Andes, Teatro de Los Andes, 2012 fot. Valentino Saldivar

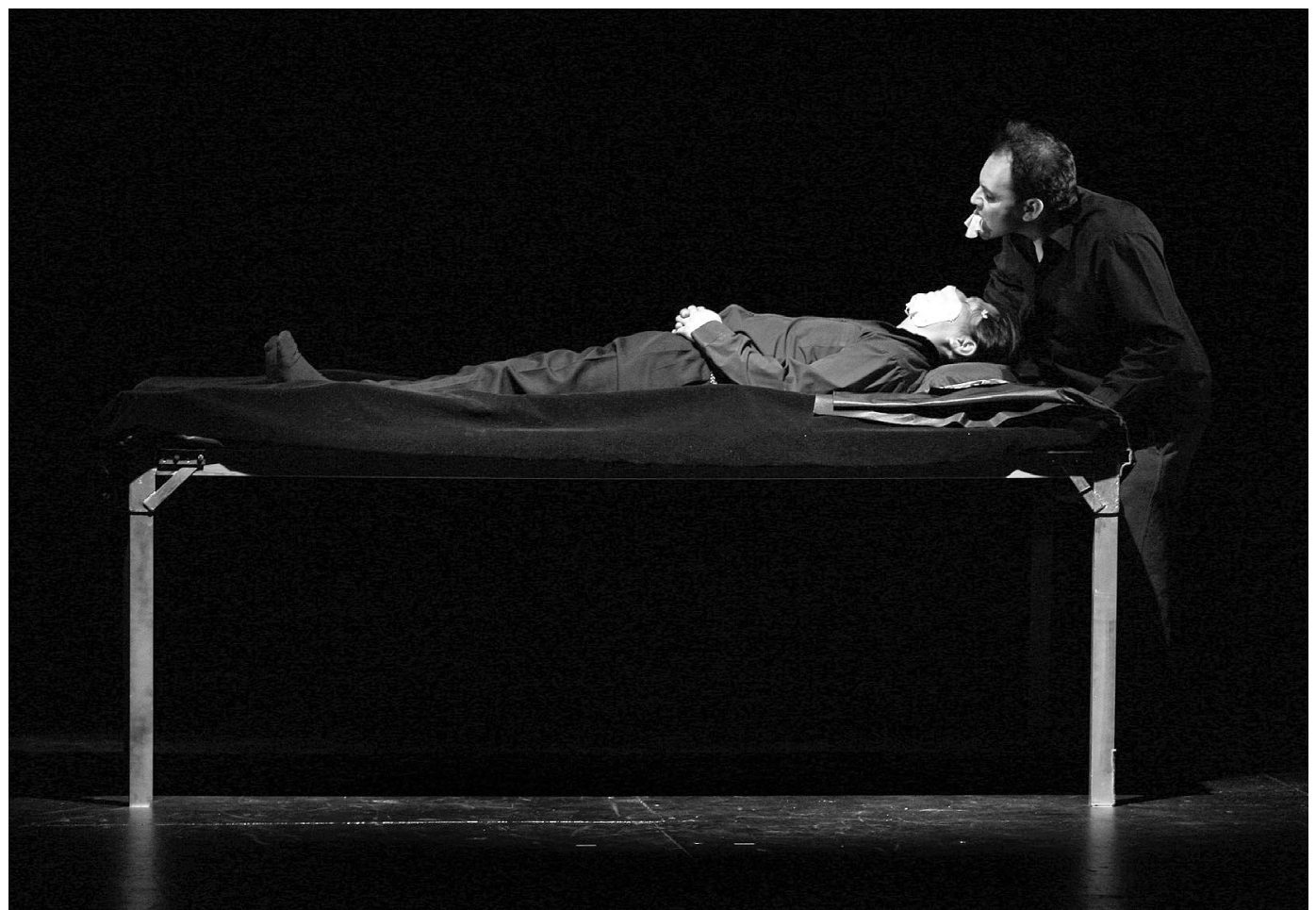

Sín título, técnica mixta, o grupo Yuyachkani (Peru) 0 Grupo Cultural Yuyachkani, de Lima, dirigido por Migue Rubio Zapata, trouxe uma obra de 2004, feita na sequência de Hechoen el Perú, de 2001, que cruza a linguagem do teatro com os códigos da exposição museológica para tratar o tema da memória cultural e trazer ao de cima factos da história nacional, desde a fundação do país até às ditaduras do final do séc. XX. Os espectadores começam por passar por uma série de pequenas vitrinas de museu onde estão amontoados vários objectos e documentos históricos, para depois entrarem numa sala onde figuram os actores do grupo, como se fossem estátuas de cera, representando figuras alegóricas da história do Peru. Nas paredes, textos e palavras de ordem vão apresentando argumentos e preparando o público. Aos poucos, as figuras ganham vida, e as plataformas, onde se encontravam, começam a deslocar-se pelo espaço, compondo uma sequência de quadros cada um mais impressionante que o outro, que culminam nos dados sobre a esterilização forçada de mulheres indígenas levada a cabo durante 0 governo de Fujimori. Com uma cenografia, música e interpretação impecáveis, e uma dramaturgia e encenação fulgurantes, Sin título, técnica mista dá conta da história do Peru (e da América Latina), ao mesmo tempo que revê e actualiza a linguagem teatral de um modo que deveria ser estudado em todo o mundo.

\section{Gemelos, do Teatro Cinema (Chile)}

Criado a partir do romance Le grand cahier, de Agota Kristof, escritora húngara exilada na Suiça em 1956, Gemelos relata a auto-educação de dois irmãos, deixados com a avó durante a guerra, e que se dedicam a criar um sistema moral próprio, de modo a sobreviverem num ambiente hostil. 0 facto de as personagens não compreenderem bem o mundo à sua volta permite à autora criticar livremente todos e quaisquer preceitos morais, descrevendo cruamente a iniciação das crianças

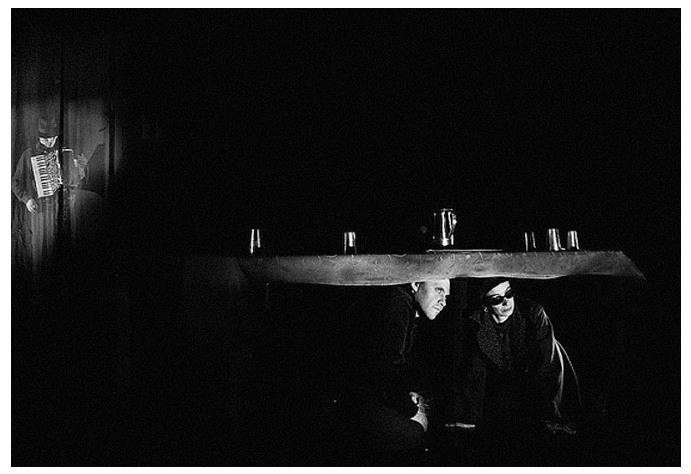

no mundo adulto. Com uma máquina de cena que tem a forma de um teatro de marionetas e os actores movimentando-se mecanicamente, o espectáculo parece ser para crianças, mas o dispositivo logo se revela uma analogia da rigidez de sentimentos que os gémeos desenvolvem, aplicável a qualquer contexto cultural.

\section{Hamlet, de los Andes, Teatro de los Andes (Bolívia)}

Esta versão de Hamlet vale pelo engenho que revela na adaptação da peça para apenas três actores e um músico. Circundando o espaço, ondulam panos de tule preto que criam um ambiente de terror. Uma mesa faz de porta, tumba e até espada; na cena em que o príncipe dinamarquês poupa a vida do tio, a mesa é suspensa em cima da cabeça deste. Em contraponto, o episódio de teatro dentro de teatro criado para desmascarar o usurpador é apresentado como uma hilariante luta de wrestling entre duas típicas indias bolivianas. Este é o outro matiz da obra, o recurso a elementos significativos da paisagem cultural da Bolívia. Órfãos de director, com a saída de Cesar Brie do grupo, o Teatro de Los Andes reinventa-se nesta obra. 